OPEN ACCESS

Edited by:

Andrea Greco,

University of Bergamo, Italy

Reviewed by:

Cristina Senín-Calderón,

University of Cádiz, Spain

Cinzia Castiglioni,

Catholic University of the Sacred

Heart, Italy

Agostino Brugnera,

University of Bergamo, Italy

*Correspondence:

Hendrik Berth

h.berth@ukdd.de

Specialty section:

This article was submitted to

Quantitative Psychology

and Measurement

a section of the journal

Frontiers in Psychology

Received: 03 July 2020 Accepted: 02 November 2020 Published: 01 December 2020

Citation:

Schmalbach I, Schmalbach B,

Zenger $M$, Berth $H$, Albani C, Petrowski K and Brähler E (2020) A

Brief Assessment of Body Image

Perception: Norm Values and Factorial Structure of the Short

Version of the FKB-20.

Front. Psychol. 11:579783.

doi: 10.3389/fpsyg.2020.579783

\section{A Brief Assessment of Body Image Perception: Norm Values and Factorial Structure of the Short Version of the FKB-20}

\author{
Ileana Schmalbach ${ }^{1,2}$, Bjarne Schmalbach ${ }^{2}$, Markus Zenger ${ }^{3,4}$, Hendrik Berth ${ }^{1 *}$, \\ Cornelia Albani ${ }^{5}$, Katja Petrowski2,5 and Elmar Brähler ${ }^{4,6}$
}

${ }^{1}$ Technische Universität Dresden, Carl Gustav Carus Faculty of Medicine, Division of Psychological and Social Medicine and Developmental Neurosciences, Research Group Applied Medical Psychology and Medical Sociology, Dresden, Germany, ${ }^{2}$ Department of Medical Psychology and Medical Sociology, Johannes-Gutenberg University Mainz, Mainz, Germany, ${ }^{3}$ Department of Applied Human Studies, University of Applied Sciences Magdeburg and Stendal, Stendal, Germany, ${ }^{4}$ Integrated Research and Treatment Center (IFB) Adiposity Diseases - Behavioral Medicine, Medical Psychology and Medical Sociology, University of Leipzig Medical Center, Leipzig, Germany, ${ }^{5}$ Department of Psychotherapy and Psychosomatic Medicine, University Hospital Leipzig, Leipzig, Germany, ${ }^{6}$ Department of Psychosomatic Medicine and Psychotherapy, University Medical Centre, Johannes Gutenberg University Mainz, Mainz, Germany

The Body Image Questionnaire-20 (FKB-20) is one of the most applied self-report measures in the context of body image assessment in German-speaking regions. A version of the FKB-20 capturing an ideal concept of body image is also available. A special property of the scale is its high sensitivity for individuals suffering from anorexia nervosa. The present research provided a short version of this scale (for both variants) and examined its validity in a representative sample $(N=2,347)$ of the German population. We utilized factor analysis methods to identify the optimal short scale of the measure, finding excellent model fit and reliability for a two-factor model (FKB-6) for both real and ideal body image. Both versions of the FKB-6 can be considered invariant across sex and age groups. Good reliability indices were shown for both versions of the FKB-6. The reliability indices were similar to those mentioned in previous studies. Our study also revealed, that large discrepancies between the real and an ideal body image are correlated with somatic and body dysmorphic symptoms. Finally, we provided norm values for comparisons of individual scores with the general population. The FKB-6 is a valid and a reliable measure that economizes assessments by clinicians and researchers.

Keywords: body image, body dysmorphia, eating disorders, ideal body image, scale construction, Body Image Questionnaire-6

\section{INTRODUCTION}

The diagnosis of body image perturbances in eating (e.g., anorexia nervosa, bulimia nervosa), and in other psychiatric disorders or illnesses involving physical changes and disturbances associated with body dissatisfaction (e.g., sexual dysfunction, conversion disorders, transsexualisms, cancer) is part of the everyday clinical practice (Albani et al., 2006a; Peterson et al., 2017; Steinfeld et al., 2017; 
Groot, 2020). In this light, treatment and recovery are major goals during therapy. To that end, the application of validated instruments to measure body image components that allow the mapping of inter-individual differences and intra-individual development processes is indispensable (Cash, 2017).

Body image is understood as a multifaceted construct comprising a perceptual and an attitudinal component. The former indicates the accuracy of an individuals' judgment of size, shape and form relative to their actual body proportions, while the latter reflects the affective dimension of the construct (Cash and Smolak, 2011; Thompson and Schaefer, 2019). The attitudinal component conveys at least two dimensions. The first involves body image appraisals and feelings toward one's appearance (evaluative-affective). The second, emphasizes cognitive-behavioral variables on one's appearance, e.g., thoughts, concerns and internalized ideals (Cash, 2012). Cash (2012) refer to this dimension as investment. Body image experiences vary across life span and situational contexts (Tiggemann, 2004; Quittkat et al., 2019). However, there are other factors that directly affect body image, such as gender, cultural and social norms, childhood experiences, as well as biological factors-among others (Daig et al., 2006; Nichols et al., 2018; Saiphoo and Vahedi, 2019). In sum, an individual's judgment on the perception of their body is strongly influenced by cognitive and affective variables, as well biological factors and social norms.

The construct of body image has its roots in clinical settings and has been applied in studies related to neurological disorders, eating or weight disorders and body dysmorphophobia (Slade, 1994; Di Cara et al., 2019; McLean and Paxton, 2019). Accordingly, it has been shown that body image is associated with psychosocial functioning (Cash and Fleming, 2002; Fatt et al., 2020). Many studies show that a negative body image is correlated with low self-esteem, depression, poor physical wellbeing, low quality of life and hypochondriasis (Cash and Smolak, 2011; Wilson et al., 2013; França et al., 2017; Becker et al., 2019), while a positive attitude is linked to high-levels of well-being, selfesteem, weight stability, self-care and physical activities as well as proactive coping behaviors (Cash and Fleming, 2002; Zanon et al., 2016; Swami et al., 2018; Sabiston et al., 2019).

Even if there are different methods for body image assessment (Löwe and Clement, 1996; Joraschky et al., 2018; Thompson and Schaefer, 2019) difficulties in operationalizing body image have been continuously claimed. For example, the insufficient evaluation of psychometric properties has been constantly pointed out (Thompson, 2004; Kling et al., 2019; Thompson and Schaefer, 2019). In the past, some researchers (Daig et al., 2006) stated that body image is not measured broadly enough, since affective, cognitive and behavioral aspects were overlooked. Such variables are essential when analyzing body image discrepancies (Daig et al., 2006; Joraschky et al., 2018), as explained by Higgins (1987) in his "self-discrepancy theory." The author described three dimensions of the self (actual, ideal, ought selves) and two perspectives: the own and the significant others'. It is suggested that individuals strive for the best possible fit between the current self-concept and internalized ideals. Discrepancies between the ideal and the current body image are related to negative appraisals, body dissatisfaction and body dysmorphic symptoms (Daig et al., 2006; Glauert et al., 2009; Vashi, 2016).

Body dissatisfaction has been increasingly observed (Halliwell et al., 2011; Wang et al., 2019). An influential contribution of this phenomena might be anchored on the discrepancy between beauty ideals (e.g., thinness for women and muscular body for males; Mills et al., 2017; Nagar and Virk, 2017) and average body sizes of women and men. Since body image dissatisfaction might have pervasive consequences for quality of life (Cash and Fleming, 2002; Mond et al., 2013) and it is also associated with a variety of psychiatric conditions, its assessment has exponentially increased (Cash, 2002; Kling et al., 2019; Thompson and Schaefer, 2019; Wang et al., 2019). Diagnosis and treatment of body image disturbances are key for psychological functioning and well-being. While there is a variety of body image measures available for English-speaking regions, the scarcity of validated scales (Kling et al., 2019) suitable for German-speaking regions has been pointed out (Löwe and Clement, 1996; Thompson, 2004; Albani et al., 2006a). From this perspective, the main purpose of the study is to provide a valid and economic tool suitable for daily clinical practice in German-speaking populations aiming to target body image concerns, by means of a short version of the FKB-20 (Fragebogen Körperbild-20 = Body Image Questionnaire-20; Löwe and Clement, 1996).

The FKB-20 is considered to be one of the most applied selfreport measures (in German-speaking areas) in its field. It was developed to diagnose body image disorders in clinical practice and measure body image-related aspects (Löwe and Clement, 1996). A peculiarity of the scale is the focus on measuring a stable concept of one's body image, rather than a current state. The FKB-20 integrates cognitive, affective and evaluative aspects of body image comprised in two subscales Rejecting Body Image (RBI; evaluations of an individual's body image regarding appearance and well-being) and Vital Body Dynamics (VBD; energetic and movement related aspects and activities). This measure has been applied in numerous studies and clinical settings, showing satisfactory psychometric properties and especially a high sensitivity to change and detect eating disorders, e.g., anorexia nervosa (Löwe and Clement, 1996; Albani et al., 2006a; Mölbert et al., 2018). It was also applied to specify body dysmorphia disorder (Sack et al., 2002; Schieber and Martin, 2016) and measure the effects of different group therapy interventions in patients with multiple sclerosis (Tesar et al., 2003; Veleva et al., 2018), cancer (Grübel, 2003; Esser et al., 2018), a heart attack (Löwe et al., 2002) and obesity (Hotter et al., 2003; Ziser et al., 2019). Besides that, it was revealed that patients with a mental illness or pronounced psychological distress reported higher values on the RBI subscale and lower values on the VBD subscale (Löwe et al., 2003). Another uniqueness of the FKB20 is the availability of a version that measures one's concept of an ideal body image. Such was validated by Daig et al. (2006) by reformulating the original items into the third person. In their research, they reported significant differences between the means of the two versions and correlations to body dysmorphic symptoms. High discrepancies were observed in young women in terms of RBI. The higher the scores on the VBD (in both versions of the scale), the lower the body dysmorphic symptoms were. 
This also holds true for the RBI, but in the opposite direction: the higher the RBI-scores (in both versions), the stronger the body dysmorphic symptoms.

Considering the growing demand for scientifically sound measures in the field of body image assessment in Germanspeaking regions and the value of such in clinical and in research settings, a short version appears convenient. Especially for patients with a background of mental illness, older participants, or for large-scale health surveys, an economical measure seems desirable. Therefore, the main aim of the present study is to develop a short scale for each version of the FKB-20 and evaluate their psychometric properties. A further aim is to provide insight of how body image perception affects relevant psychological variables. For this purpose, we explored discrepancies between the real $\left(\mathrm{FKB}-6_{\text {real }}\right)$ and the ideal body image (FKB- $\left.6_{\text {ideal }}\right)$ and their relation to: physical and subjective well-being, quality of life, somatoform and body dysmorphic symptoms.

To provide evidence of the validity of the $F K B-20$, correlations with the following measures will be evaluated: Questionnaire for assessing subjective physical well-being (FEW), EURO-HIS-QOL8 (Health Related Index of Quality of Life), The World Health Organization-Five Well-Being Index (WHO-5), Screening for Somatoform Disorders (SOMS) and Body dysmorphic symptoms inventory (BDSI). Physical well-being (FEW), quality of life (HISQOL-8) and subjective well-being (WHO-5) are expected to be positively associated to VBD, but weakly or negatively related to RBI (FKB-6 real, ideal $_{\text {; }}$ Cash and Fleming, 2002; Sinclair and Myers, 2004; Williams et al., 2004; Rief et al., 2006). In addition, somatoform (SOMS) and body dysmorphic symptoms (BDSI) are expected to positively correlate with RBI, but negatively with VBD (FKB-6 real,ideal ; McCaulay et al., 1988; Carlson, 2004; Tiggemann, 2004; Sarwer et al., 2005; Cash and Smolak, 2011). Moreover, we hypothesized that discrepancies between the real and the ideal body image (in both dimensions: VBD, RBI) will be positively correlated with somatoform and body dysmorphic symptoms and negatively with physical and subjective well-being as well as with quality of life (Daig et al., 2006; Glauert et al., 2009).

\section{MATERIALS AND METHODS}

\section{Participants and Procedure}

The data in the present study were collected on behalf of the local university, supported by a demographic research institute (USUMA, Berlin) as part of a population-based representative survey using a multistage sampling. The participants were selected by a random-route method and visited at home by trained and experienced interviewers from the research institute USUMA, Berlin. From all the household members the target participant at home was also randomly selected (Kish-SelectionGrid). Inclusion criteria required subjects to be at least 14 years of age in addition to sufficient command of the German language. As part of the interviews, participants filled in self-report questionnaires (participation was voluntarily). Each respondent received a signed privacy policy form. Parents or legal guardians signed a consent form approving the participating of underaged subjects. The response rate of the survey was
62.3\%. Drop outs were due to dismissal of participation by the household (14\%) or by the target subject (9.4\%), failed attempts to contact the selected household (9\%) and the target subject (3.6\%). Additionally, some interviews were invalid $(n=39$; items missing values). The final sample consists a total of $N=2,429$ participants between 14 and 99 years of age (50.35; $S D=17.44)$, with $52.9 \%$ of the subjects being female. The methods of data collection were in accordance with the Helsinki Declaration of 1975 (as revised in 1983). Further details on the sociodemographic composition of the sample are described in Table 1. The sample is representative in terms of respondent age and sex when compared to data from the Federal Statistical Office of Germany (2019). There were no significant deviations as per $\chi^{2} \leq 4.00, p \geq 0.550, V \leq 0.063$. However, - at least descriptively - we acknowledge a underrepresentation of individuals of age 70 or older.

\section{Instruments}

\section{Body Image Questionnaire (FKB-20; Clement and Löwe, 1996; Albani et al., 2006a)}

This scale measures cognitive, affective, and evaluative variables of an individual's concept of body image and reflects relatively time-stable physical aspects, rather than current physical conditions. The questionnaire comprises two subscales: Rejecting Body Image ( $\alpha=0.80$; e.g., My body is often a burden to me, I am not happy with my body shape) and Vital Body Dynamics ( $\alpha=0.90$; e.g., I am healthy, I am in top shape) with 10 items each, ranging from $1=$ it does not apply to $5=$ it applies. The subscale scores are calculated by summing up the item values. Satisfactory psychometric values have been demonstrated in previous studies (e.g., Grübel, 2003; Tesar et al., 2003; Albani et al., 2006a; Daig et al., 2006). For the ideal body image version of the FKB-20 (Daig et al., 2006), the original items were rephrased into the third person. Participants were asked to picture a person of the same age and gender and describe their ideal physical sensations as well as an optimal body image (e.g., "He/She feels full of strength"). In the present study, the correlations between the real and ideal body image versions were high: VBD $r=0.73$, RBI $r=0.62$ and Cronbach's Alpha values (for both versions) were satisfactory $(\mathrm{VBD}=\alpha=0.88, \mathrm{RBI}=\alpha=0.86)$.

EURO-HIS-QOL-8 (EURO-Health Related Index of Quality of Life-8; Brähler et al., 2007). This scale assesses the general quality of life regarding psychological, physical, social, and environmental variables. It comprises 8 items which refer to the short version of the two questionnaires WHO-QOL-100 (Power et al., 1999) and WHO-QOL-BREF (Skevington et al., 2004). Answers are to be rated on a five-point scale $(1=$ very bad to $5=$ very good) based on the past 2 weeks. The total score is achieved by summing up the item scores. Extensive surveys with the questionnaire provide evidence of good psychometric properties ( $\alpha=0.80-0.92$; Gunzelmann et al., 2006; Schmidt et al., 2006).

\section{World Health Organization Well-Being Index-5 (WHO-5; Brähler et al., 2007)}

This measure is a short version of the WHO-10 (Bech et al., 1996) and it has been translated into more than 30 languages. 
TABLE 1 | Sample description with group comparisons for the FKB-6.

\begin{tabular}{|c|c|c|c|c|c|c|c|}
\hline & \multirow[t]{3}{*}{$n$} & \multirow[t]{3}{*}{$\%$} & \multirow[t]{3}{*}{$\%$ in pop. } & \multicolumn{4}{|c|}{ FBK-6, $M(S D)$} \\
\hline & & & & \multicolumn{2}{|c|}{ Real body image-version } & \multicolumn{2}{|c|}{ Ideal body image-version } \\
\hline & & & & RBI & VBD & RBI & VBD \\
\hline Sex & & & & $\begin{array}{l}F(1,2,366)=27.061 \\
p=0.001, \eta^{2} p=0.011\end{array}$ & $\begin{array}{c}F(1,2,366)=28.090, \\
p=0.001, \eta^{2} p=0.012\end{array}$ & $\begin{array}{c}F(1,2,366)=12.118, \\
p=0.001, \eta^{2} p=0.005\end{array}$ & $\begin{array}{c}F(1,2,366)=17.082, \\
p=0.001, \eta^{2} p=0.007\end{array}$ \\
\hline Female & 1,186 & 50.4 & 50.7 & $1.840(0.841)$ & $3.611(0.907)$ & $1.911(0.837)$ & $3.746(0.866)$ \\
\hline Male & 1,167 & 49.6 & 49.3 & $1.663(0.810)$ & $3.812(0.937)$ & $1.791(0.845)$ & $3.897(0.911)$ \\
\hline $\begin{array}{l}\text { Age } \\
(M=46.16 \\
S D=17.98)\end{array}$ & & & & $\begin{array}{c}F(5,2,366)=2.277 \\
p=0.045, \eta^{2} p=0.005\end{array}$ & $\begin{array}{l}F(5,2,366)=111.162 \\
p=.001, \eta^{2} p=0.191\end{array}$ & $\begin{array}{c}F(5,2,366)=1.531 \\
p=0.177, \eta^{2} p=0.003\end{array}$ & $\begin{array}{c}F(5,2,366)=73.949 \\
p=0.001, \eta^{2} p=0.135\end{array}$ \\
\hline $18-29$ & 491 & 20.9 & 20.4 & $1.690(0.848)$ & $4.189(0.789)$ & $1.852(0.885)$ & $4.156(0.791)$ \\
\hline 30-39 & 442 & 18.8 & 14.4 & $1.678(0.812)$ & $4.021(0.794)$ & $1.804(0.838)$ & $4.081(0.731)$ \\
\hline $40-49$ & 417 & 17.7 & 14.8 & $1.811(0.869)$ & $3.838(0.823)$ & $1.833(0.822)$ & $3.981(0.782)$ \\
\hline $50-59$ & 337 & 14.3 & 18.5 & $1.812(0.862)$ & $3.657(0.888)$ & $1.914(0.925)$ & $3.981(0.782)$ \\
\hline $60-69$ & 416 & 17.7 & 13.9 & $1.802(0.799)$ & $3.357(0.831)$ & $1.917(0.799)$ & $3.787(.861)$ \\
\hline$\geq 70$ & 251 & 10.7 & 18.0 & $1.747(0.777)$ & $2.932(0.913)$ & $1.791(0.769)$ & $3.154(1.001)$ \\
\hline Education & & & & $\begin{array}{l}F(3,2,366)=12.458 \\
p=0.001, \eta^{2} p=0.016\end{array}$ & $\begin{array}{c}F(3,2,366)=63.914 \\
p=0.001, \eta^{2}{ }_{p}=0.075\end{array}$ & $\begin{array}{c}F(3,2,366)=0.813, \\
p=0.487, \eta^{2}{ }_{p}=0.001\end{array}$ & $\begin{array}{c}F(3,2,366)=36.558 \\
p=0.001, \eta^{2}{ }_{p}=0.044\end{array}$ \\
\hline$\leq 9$ years & 1,060 & 45.0 & & $1.845(0.858)$ & $3.438(0.942)$ & $1.882(0.849)$ & $3.621(0.911)$ \\
\hline 10 years & 793 & 33.7 & & $1.740(0.841)$ & $3.906(0.841)$ & $1.827(0.830)$ & $3.954(0.838)$ \\
\hline$\geq 11$ years & 412 & 17.5 & & $1.557(0.686)$ & $3.955(0.869)$ & $1.828(0.845)$ & $4.018(0.835)$ \\
\hline $\begin{array}{l}\text { School } \\
\text { students }\end{array}$ & 88 & 3.7 & & $1.700(0.870)$ & $4.231(0.766)$ & $1.841(0.895)$ & $4.220(0.824)$ \\
\hline Family & & & & $\begin{array}{l}F(5,2,366)=63.914, \\
p=0.001, \eta^{2} p=0.191\end{array}$ & $\begin{array}{c}F(5,2,366)=59.897, \\
p=0.001, \eta^{2} p=0.113\end{array}$ & $\begin{array}{c}F(5,2,366)=3.158, \\
p=0.008, \eta^{2} p=0.007\end{array}$ & $\begin{array}{c}F(5,2,366)=39.785 \\
p=0.001, \eta^{2}{ }_{p}=0.078\end{array}$ \\
\hline Married & 1,420 & 60.4 & & $1.719(0.812)$ & $3.727(0.876)$ & $1.828(0.835)$ & $3.843(0.855)$ \\
\hline $\begin{array}{l}\text { Committed } \\
\text { relationship }\end{array}$ & 103 & 4.4 & & $1.670(0.759)$ & $4.010(0.889)$ & $1.770(0.787)$ & $3.974(0.721)$ \\
\hline Single & 464 & 19.7 & & $1.752(0.877)$ & $4.058(0.846)$ & $1.881(0.877)$ & $4.037(0.858)$ \\
\hline Separated & 22 & 1.6 & & $1.892(1.000)$ & $3.535(0.857)$ & $2.107(0.902)$ & $3.666(0.551)$ \\
\hline Divorced & 164 & 7.0 & & $1.825(0.833)$ & $3.672(0.887)$ & $1.765(0.808)$ & $3.946(0.846)$ \\
\hline Widowed & 179 & 7.6 & & 1.875 (0.823) & $2.945(0.899)$ & 1.997 (0.843) & $3.170(0.935)$ \\
\hline Employment & & & & $\begin{array}{c}F(4,2,366)=3.263 \\
p=0.011, \eta^{2} p=0.005\end{array}$ & $\begin{array}{l}F(4,2,366)=125.498 \\
p=0.001, \eta^{2}{ }_{p}=0.175\end{array}$ & $\begin{array}{c}F(4,2,366)=0.739 \\
p=0.565, \eta^{2}{ }_{p}=0.001\end{array}$ & $\begin{array}{c}F(4,2,366)=74.190 \\
p=0.001, \eta^{2}{ }_{p}=0.112\end{array}$ \\
\hline Working fulltime & 886 & 37.7 & & $1.723(0.851)$ & $4.024(0.781)$ & $1.825(0.877)$ & $4.047(0.781)$ \\
\hline $\begin{array}{l}\text { Working part- } \\
\text { time }\end{array}$ & 228 & 9.7 & & $1.742(0.787)$ & $3.821(0.823)$ & $1.842(0.733)$ & 3.975 (0.7003) \\
\hline Unemployed & 375 & 15.9 & & $1.849(0.885)$ & $3.705(0.880)$ & $1.907(0.895)$ & $3.832(0.857)$ \\
\hline Retired & 629 & 26.7 & & $1.788(0.809)$ & $3.146(0.917)$ & $1.853(0.802)$ & $3.380(0.954)$ \\
\hline In training & 234 & 10.0 & & $1.608(0.729)$ & $4.207(0.771)$ & $1.891(0.850)$ & $4.177(0.779)$ \\
\hline
\end{tabular}

FBK-6 = Six-item version of the Body Image Questionnaire; \% in pop = Distributions in the German general population, according to the Federal Statistical Office of Germany (2019). 
The WHO-5 measures subjective psychological well-being by means of five positively phrased items. Each item is scored from $5=$ all of the time to $0=$ at no time, referring to a period within the past 2 weeks. The raw score ranges from $0=$ absence of well-being to $25=$ maximal well-being. The scale has been validated and applied in different settings showing satisfactory psychometric properties $(\alpha=0.89-0.95$; Heun et al., 2001; De Wit et al., 2007; Krieger et al., 2014; Topp et al., 2015).

\section{Questionnaire for Assessing Subjective Physical Well-Being (FEW; Kolip and Schmidt, 1999; Albani et al., 2006b)}

The questionnaire is applied to measure habitual physical well-being (and not the absence of complaints) by means of four dimensions: resilience, vitality, enjoyment, and inner peace. Each scale has four exclusive positively formulated items rated from $0=$ does not apply at all to $5=$ applies completely. The scale values are calculated as mean values of the associated items. The total value is calculated as the mean value of the four scales. Psychometrics are satisfactory $(\alpha=0.88-0.93)$. Norm values are available (Albani et al., 2006a).

\section{Body Dysmorphic Symptoms Inventory (BDSI; Buhlmann et al., 2009)}

The BDSI is a screening tool that measures the severity of symptoms related to body dysmorphia, such as excessive preoccupation with disliked body parts and suicidality. The questionnaire also captures how much time is employed in worries and concerns related to disliked body regions $(0=I$ don't think about it to $4=$ over $8 \mathrm{~h} /$ day or more), as well as the extent of ritualized, appearance-related actions $(0=$ not at all to $4=$ over $8 \mathrm{~h}$ /day or more). Furthermore, it reflects the strain and impairment caused in daily tasks due to preoccupation with body concerns. The scale is a self-report instrument comprising 18 items. Questions two and three serve as auxiliary items to detect eating disorders and are not included in the total score. The score of the BDSI ranges from 0 to 64. Additionally, four items capture the criteria of a body dysmorphic disorder based on the DSM-IV (Rief et al., 2006). Psychometric properties are satisfactory ( $\alpha=0.88$; Buhlmann et al., 2009).

\section{Screening for Somatoform Disorders (SOMS; Rief et al., 1997)}

The SOMS serves as a screening tool for the criteria of somatoform disorders according to ICD-10 and DSM-IV. It assesses 53 symptoms that had been present in the past 7 days. Each symptom is rated according to its degree of associated impairment $1=$ mild to $4=$ very severe. In the present study we focus on the severity index for somatization (SSI), which is computed by summing up the item scores. The psychometric properties of the scale have shown satisfactory values in previous studies ( $\alpha=0.88-0.92$; Rief et al., 1997; Hessel et al., 2002; Rief and Hiller, 2003; Hiller et al., 2006). The SSI discriminated patients with somatoform disorders from those with other forms of mental disorders.

\section{Statistical Analyses}

All analyses were conducted in $R$, using the packages EFAutilities, ezCutoffs, lavaan, multilevel, psych, semTools, and stuart (Rosseel, 2012; Bliese, 2016; Revelle, 2018; Schmalbach et al., 2019; Schultze, 2019; Zhang et al., 2019; Jorgensen et al., 2020). Initially, we randomly split our full sample $(N=2,347)$ into an exploratory $(n=1,147)$ and a confirmatory one $(n=1,200)$. This will allow for independent testing in the confirmatory sample of the model generated in the exploratory sample. To determine the number of substantial factors, we then conducted parallel analysis (Horn, 1965). This procedure compares the raw, empirical eigenvalues to eigenvalues of randomly generated covariance matrices with the same properties as the original data set-and their 99\% confidence interval.

Next, we used several methods of item reduction and model generation. First, we conducted exploratory factor analysis using ordinary least squares extraction and oblique rotation. Second, we examined item descriptive statistics. We then discarded all items that either exhibited loadings smaller than 0.500 , item-total correlations smaller than 0.500 , or absolute skewness and excessive kurtosis values larger than 2 or 4 , respectively (Hair et al., 2013; Kim, 2013), or several of the above. Third, we used stuart to further reduce the item pool and generate a shortened model-with three items per factor-for testing in the confirmatory sample. Stuart utilizes ant colony optimization to construct and test subsets of a scale and maximize model fit. In addition, we constrained the algorithm to prefer solutions that are strongly invariant across participant's gender.

We then ran confirmatory factor analysis based on robust maximum likelihood estimation (Satorra and Bentler, 2001) to test model fit in the confirmatory sample. To evaluate model fit, we inspected $\chi^{2}$ and the following model fit indices, comparing them to the commonly employed cut-off values: The Comparative Fit Index (CFI), the Tucker-Lewis-Index (TLI), the Root Mean Square Error of Approximation (RMSEA), and the Standardized Root Mean Square Residual (SRMR). CFI and TLI should be larger than 0.950, and RMSEA and SRMR should be smaller than 0.06 to evince good fit ( $\mathrm{Hu}$ and Bentler, 1999; Schermelleh-Engel et al., 2003). To supplement these generic cut-off values, we calculated simulated cut-offs using ezCutoffs (Schmalbach et al., 2019). Using 1,000 simulated data sets based on the same number of observations and the same population model, ideal fit index cut-off values are determined empirically. Furthermore, it should be noted that we the utilized robust formulas for the estimation of CFI, TLI, and RMSEA (Broesseau-liard et al., 2012; Brosseau-Liard and Savalei, 2014). For the analysis of measurement invariance, we utilized the common procedure of comparing increasingly restrictive models (configural, metric, scalar, strict; Milfont and Fischer, 2010). If the differences in scaled $\chi^{2}$, robust CFI and robust RMSEA were non-significant and smaller than or equal to 0.01 for $C F I$ and 0.015 for RMSEA, respectively, we judged it as evidence for measurement invariance (Chen, 2007). Finally, we used $\omega$ as a measure of factor score reliability (Dunn et al., 2014). 


\section{RESULTS}

\section{Item Reduction}

The results of the EFA and the item descriptive analyses are reported in Tables 2, 3a, b. Parallel analysis revealed clear evidence for a two-factorial structure, which was mirrored in the EFA results: Items 5, 13, and 19 exhibited loadings smaller than 0.500 , crossloadings, or both. In addition, corrected item-total correlations exceeded 0.500 for all items except Items 5, 13, and 19. We supplemented these analyses by applying an analysis based on item response theory and investigated item discrimination parameters using a graded response model in the mirt package (Chalmers, 2012): Similar to the results from the EFA, Items 5, 13, and 19 evinced the lowest discrimination for the Rejecting Body Image scale. According to Baker (2001), Item 5 had low discrimination $\left(a_{5}=0.51\right)$, and Items 13 and 19 had moderate discrimination $\left(a_{13}=1.13, a_{19}=1.28\right)$. All other items had high or very high discrimination. For the Vital Body Dynamic scale, only Item 20 had a discrimination parameter which was not at least high $\left(a_{20}=1.12\right)$.

By investigating skewness and kurtosis, we were able to eliminate Items 10 and 11 as a highly non-normally distributed items, with the vast majority of participants choosing the lowest response option. After eliminating these five items, we used the remaining 16 items as input for model generation in stuart. Among the possible 1,200 combinations, the algorithm selected those items marked in Table 2. In the exploratory sample, this solution evinced excellent fit, $\chi^{2}(24)=51.850$,

TABLE 2 | Results of the parallel analysis.

\begin{tabular}{ccc}
\hline & Raw eigenvalues & 99th percentile \\
\hline 1 & 7.08 & 1.29 \\
2 & 3.34 & 1.24 \\
3 & 0.88 & 1.20 \\
4 & 0.77 & 1.17 \\
\hline
\end{tabular}

TABLE 3a | Item descriptive statistics and factor loadings in confirmatory factor analysis real body image-version.

\begin{tabular}{|c|c|c|c|c|c|c|c|}
\hline & \multirow[b]{2}{*}{$M$} & \multirow[b]{2}{*}{$S D$} & \multirow[b]{2}{*}{$\gamma 1$} & \multirow[b]{2}{*}{$\gamma 2$} & \multirow[b]{2}{*}{$r_{i t}$} & \multicolumn{2}{|c|}{ CFA } \\
\hline & & & & & & VBD & RBI \\
\hline Item $3^{a}$ & 3.919 & 1.044 & -0.978 & 0.535 & 0.750 & 0.806 & \\
\hline Item $7^{a}$ & 3.647 & 0.972 & -0.577 & -0.014 & 0.803 & 0.865 & \\
\hline Item $14^{a}$ & 3.556 & 1.071 & -0.588 & -0.192 & 0.810 & 0.848 & \\
\hline Item $6^{b}$ & 1.588 & 0.950 & 1.667 & 2.112 & 0.617 & & 0.797 \\
\hline Item $8^{b}$ & 2.041 & 1.127 & 0.818 & -0.339 & 0.480 & & 0.540 \\
\hline Item $10^{b}$ & 1.637 & 0.968 & 1.571 & 1.887 & 0.665 & & 0.827 \\
\hline FBK-6 RBI & 1.755 & 0.831 & 1.2212 & 1.089 & & & \\
\hline FBK-6 VBD & 3.707 & 0.927 & -0.698 & 0.039 & & & \\
\hline
\end{tabular}

$\gamma 1$, skewness; $\gamma 2$, kurtosis; $r_{i t}$, corrected item-total correlation; RBI, Rejecting Body Image; VBD, Vital Body Dynamic. apart of the VBD subscale according to the manual. ${ }^{b}$ Part of the RBI subscale according to the manual.
TABLE 3b | Item descriptive statistics and factor loadings in confirmatory factor analysis-ideal body image version.

\begin{tabular}{|c|c|c|c|c|c|c|c|}
\hline & \multirow[b]{2}{*}{$M$} & \multirow[b]{2}{*}{$S D$} & \multirow[b]{2}{*}{$\gamma 1$} & \multirow[b]{2}{*}{$\gamma^{2}$} & \multirow[b]{2}{*}{$r_{i t}$} & \multicolumn{2}{|c|}{ CFA } \\
\hline & & & & & & VBD & RBI \\
\hline Item $3^{a}$ & 3.961 & 0.997 & -0.927 & 0.501 & 0.701 & 0.807 & \\
\hline Item $7^{a}$ & 3.773 & 0.987 & -0.682 & 0.106 & 0.748 & 0.806 & \\
\hline Item $14^{a}$ & 3.721 & 1.051 & -0.677 & -0.027 & 0.754 & 0.823 & \\
\hline Item $6^{b}$ & 1.726 & 0.983 & 1.286 & 0.863 & 0.572 & & 0.763 \\
\hline Item $8^{b}$ & 2.102 & 1.119 & 0.764 & -0.290 & 0.538 & & 0.659 \\
\hline Item $10^{b}$ & 1.731 & 0.990 & 1.324 & 1.086 & 0.600 & & 0.729 \\
\hline FBK-6 RBI & 1.853 & 0.843 & 0.891 & 0.115 & & & \\
\hline FBK-6 VBD & 3.818 & 0.891 & -0.675 & 0.077 & & & \\
\hline
\end{tabular}

$\gamma 1$, skewness; $\gamma 2$, kurtosis; $r_{i t}$ corrected item-total correlation; RBI, Rejecting Body Image; VBD, Vital Body Dynamic. " Part of the VBD subscale according to the manual; 'b Part of the RB/ subscale according to the manual.

$p<0.001, \quad C F I=0.992$, TLI $=0.989$, RMSEA $(90 \%$ $C I)=0.044(0.028 ; 0.061), S R M R=0.033$. The item intercorrelations exceed 0.300 for all scales, and are, thus, satisfactory (Nunally and Bernstein, 1994).

\section{Confirmatory Analyses}

We then tested this configuration in the confirmatory subsample, and were able to affirm the very good fit, $\chi^{2}(8)=20.488$, $p=0.009, C F I=0.995, T L I=0.991, R M S E A(90 \% C I)=0.040$ $(0.019 ; 0.062), S R M R=0.021$. As fixed rules of thumb for model fit evaluation have been criticized again and again (cf. Nye and Drasgow, 2011; McNeish et al., 2018), we utilized the simulation-based approach implemented in the $\mathrm{R}$ package ezCutoffs (Schmalbach et al., 2019) to determine model-specific cut-off values: $\chi^{2}=19.998, C F I=0.993, T L I=0.987$, $R M S E A=0.036$, and $S R M R=0.024$. Three of the five empirical indices were acceptable according to these cut-offs. Standardized factor loadings were greater than or equal to $\lambda=0.645$ for all six indicators, and the latent variables correlated at $r=-0.445$. Reliability for both subscales was good, $\omega_{V B D}=0.878$ and $\omega_{R B I}=0.757$-particularly considering the brevity of the scales (6 items in total).

\section{Ideal Body Image Version}

A confirmatory analysis was also computed for the short form of the ideal version of the FKB-20. Results show a very good fit, $\chi^{2}(8)=18.438, p=0.018, C F I=0.994$, TLI $=0.989$, RMSEA $(90 \% C I)=0.041(0.016 ; 0.065), S R M R=0.021$. Here four of the five fit measures where acceptable according to the simulated cut-offs, $\chi^{2}=21.799, C F I=0.992, T L I=0.984$, RMSEA $=0.038$, and $S R M R=0.025$. Standardized factor loadings were greater than or equal to $\lambda=0.645$ for all six indicators and the latent variables correlated at $r=-0.570$. Reliability for both subscales was good, $\omega_{V B D}=0.853$ and $\omega_{R B I}=0.756$.

Next, we tested for measurement invariance in both questionnaire variants $\left(\mathrm{FKB}-6_{\text {real, ideal }}\right.$-see Tables $\left.4 \mathbf{4 a}, \mathbf{b}\right)$ across sex and age groups using the confirmatory and the full sample, respectively. For both variants no meaningful 
TABLE 4a | Tests of measurement invariance of the FKB-6 real.

\begin{tabular}{|c|c|c|c|c|c|c|c|c|}
\hline Model & $\chi^{2}(d f)$ & $\Delta \chi^{2}$ & $\Delta d f$ & $p$ & CFI & $\Delta C F I$ & RMSEA & $\triangle R M S E A$ \\
\hline \multicolumn{9}{|l|}{ Sex } \\
\hline Configural invariance & $26.352(16)$ & & & & 0.996 & & 0.037 & \\
\hline Female & $21.838(8)$ & & & & 0.988 & & 0.059 & \\
\hline Male & $4.745(8)$ & & & & 1 & & 0.000 & \\
\hline Metric invariance & $27.508(20)$ & 1.156 & 4 & 0.121 & 0.997 & 0.001 & 0.028 & 0.009 \\
\hline Scalar invariance & $57.165(24)$ & 29.658 & 4 & 0.001 & 0.987 & 0.010 & 0.052 & 0.024 \\
\hline Partial scalar invariance ${ }^{a}$ & $41.841(23)$ & 14.333 & 3 & 0.009 & 0.993 & 0.004 & 0.041 & 0.013 \\
\hline Partial strict invariance ${ }^{a}$ & $52.178(29)$ & 10.337 & 6 & 0.005 & 0.989 & 0.004 & 0.043 & 0.002 \\
\hline \multicolumn{9}{|l|}{ Age } \\
\hline Configural invariance & $80.194(48)$ & & & & 0.993 & & 0.047 & \\
\hline $18-29$ & $13.512(8)$ & & & & 0.993 & & 0.044 & \\
\hline 30-39 & $13.625(8)$ & & & & 0.991 & & 0.053 & \\
\hline $40-49$ & $12.810(8)$ & & & & 0.995 & & 0.040 & \\
\hline $50-59$ & $12.640(8)$ & & & & 0.993 & & 0.048 & \\
\hline $60-69$ & $15.901(8)$ & & & & 0.991 & & 0.051 & \\
\hline$\geq 70$ & $11.702(8)$ & & & & 0.994 & & 0.042 & \\
\hline Metric invariance & $105.688(68)$ & 25.493 & 20 & 0.002 & 0.992 & 0.001 & 0.042 & 0.005 \\
\hline Scalar invariance & $136.984(88)$ & 31.296 & 20 & 0.006 & 0.990 & 0.002 & 0.041 & 0.001 \\
\hline Strict invariance & $164.732(128)$ & 27.748 & 40 & 0.015 & 0.988 & 0.002 & 0.038 & 0.003 \\
\hline
\end{tabular}

a The intercept of Item 8 was freed to vary between groups.

TABLE 4b | Tests of measurement invariance of the FKB-6 ideal.

\begin{tabular}{|c|c|c|c|c|c|c|c|c|}
\hline Model & $\chi^{2}(d f)$ & $\Delta \chi^{2}$ & $\Delta d f$ & $p$ & CFI & $\Delta C F I$ & RMSEA & $\triangle R M S E A$ \\
\hline \multicolumn{9}{|l|}{ Sex } \\
\hline Configural invariance & $25.907(16)$ & & & & 0.994 & & 0.040 & \\
\hline Female & $17.694(8)$ & & & & 0.990 & & 0.052 & \\
\hline Male & $9.318(8)$ & & & & 0.998 & & 0.022 & \\
\hline Metric invariance & $27.903(20)$ & 1.996 & 4 & 0.111 & 0.996 & 0.002 & 0.031 & 0.009 \\
\hline Scalar invariance & $34.174(24)$ & 6.271 & 4 & 0.081 & 0.995 & 0.001 & 0.032 & 0.001 \\
\hline Strict invariance & $41.552(30)$ & 7.377 & 6 & 0.078 & 0.993 & 0.002 & 0.032 & 0.000 \\
\hline \multicolumn{9}{|l|}{ Age } \\
\hline Configural invariance & $67.325(48)$ & & & & 0.994 & & 0.040 & \\
\hline $18-29$ & $11.170(8)$ & & & & 0.995 & & 0.037 & \\
\hline $30-39$ & $3.683(8)$ & & & & 1.00 & & 0.000 & \\
\hline $40-49$ & $10.346(8)$ & & & & 0.996 & & 0.034 & \\
\hline $50-59$ & $10.736(8)$ & & & & 0.994 & & 0.044 & \\
\hline $60-69$ & $14.981(8)$ & & & & 0.989 & & 0.052 & \\
\hline$\geq 70$ & $20.438(8)$ & & & & 0.978 & & 0.078 & \\
\hline Metric invariance & $91.364(68)$ & 24.039 & 20 & 0.030 & 0.993 & 0.001 & 0.036 & 0.004 \\
\hline Scalar invariance & $115.355(88)$ & 23.991 & 20 & 0.026 & 0.993 & 0.000 & 0.033 & 0.003 \\
\hline Strict invariance & $138.220(128)$ & 22.864 & 40 & 0.253 & 0.994 & 0.001 & 0.026 & 0.007 \\
\hline
\end{tabular}

deviation was observed when considering age groups, as evidenced by strict factorial invariance. This indicates that group means resulting from the measurement model can be compared meaningfully. This was also true when analyzing sex for the ideal body image model, but not for the real body image model. Here we observed evidence for metric invariance, but then we found substantial differences in terms of the item intercepts. In particular, items 8 and 10 of the RBI scale evinced standardized intercept differences of $\Delta \nu=-0.354$ and -0.253 , respectively. Negative values mean that females score higher than males on this item at the same factor score. In contrast, men scored higher on items 7 and 14 of the VBD scale, as evidenced by positive standardized intercept differences of $\Delta \nu=0.291$ and 0.256 , respectively. By allowing the intercept of item 8 to vary between groups, we established partial strict invariance across sexes (Steenkamp and Baumgartner, 1998). 
Finally, it could be confirmed that discrepancies between the real and the ideal body image (in VBD and $\mathrm{RBI}$ ) are positively associated with somatoform $(\mathrm{VBD}=0.184 ; \mathrm{RBI}=0.071)$ and body dysmorphic symptoms $(\mathrm{VBD}=0.141$; RBI $=0.142)$ and negatively with physical and subjective well-being as well as with quality of life. As seen in Table 6, low to moderate correlations were shown.

\section{Validity Correlations}

We correlated the scales of the real and the ideal version of the FKB-6 with other related measures to test convergent validity (see Table 5). Correlations were present as hypothesized. Physical and subjective well-being, as well as quality of life are positively correlated with $\mathrm{VBD}$, but negatively related to RBI. As shown in Table 5 the strongest positive correlation in terms of VBD was with resilience subscale of the FEW $\left(r_{\text {real }}=0.77 ; r_{\text {ideal }}=0.56\right)$, while the weakest was with somatic symptoms $\left(r_{\text {real }}=-0.53 ; r_{\text {ideal }}=-0.40\right)$. As further hypothesized, somatoform and body dysmorphic symptoms were positive correlated with RBI, but negatively or low with VBD. The highest positive correlation in terms of RBI was with specific symptoms of the BDSI scale $\left(r_{\text {real }}=0.49 ; r_{\text {ideal }}=0.38\right)$, while the lowest was with health-related quality of life $\left(r_{\text {real }}=-0.41\right.$; $r_{\text {ideal }}=-0.32$ ).

\section{Sociodemographic Influences}

We tested for differences in the subscales of the real and ideal body image scale with regard to sociodemographic variables (see Table 1). Almost all comparisons were significant, which was expected given the sample size. Age, family status, and education had barely an effect in explaining differences in body image rejection (in both versions). Regardless, the two last variables did have a very small effect, but only in the real body image version. On the other hand, sex and education (real version) exhibited slightly larger effect sizes. The largest effect was, however, traceable to family status (real version) which explained close to $20 \%$ of variance.
In terms of vital body dynamics sex (ideal version) had barely an effect in explaining differences. However, in the real version sex exhibited a slightly larger effect size, as well as education (both versions) and family status (ideal version). The largest effect was attributed to age and employment (both versions) which explained more than $10 \%$ of the variance.

In sum, compared to other variables family status had the largest effect in explaining differences concerning rejecting body image (real version). With reference to vital body dynamics age and employment were the most influential variables (both versions).

\section{Norm Values}

In Tables 7-7c, we report percentile ranks partitioned by sex and by age groups.

\section{DISCUSSION}

The main aim of the present study was to provide a short version of the FKB-20 (real and ideal version) and demonstrate its validity by means of associated constructs. Such a measure would economize clinical assessments and research endeavors. A further aim, was to illustrate the effects related to discrepancies between a real and an ideal body image, in the matter of somatic and body dysmorphic symptoms, quality of life, psychological and physical well-being.

The psychometric analyses evinced satisfactory results for both versions of the scale. The reliability indices were similar to those mentioned in previous studies (Clement and Löwe, 1996; Albani et al., 2006a,b; Daig et al., 2006; Hinz et al., 2010). The overall results suggested that both short versions of the FKB are valid and reliable providing accurate measurement of appraisals, feelings, and dynamics related to body image issues. Further, it was revealed that large discrepancies between a real and an ideal body image are correlated with somatic and body dysmorphic symptoms, leading to chronic stress and reduced well-being, as previously

TABLE 5 | Associations of the real and ideal version of the FKB-6 with related measures.

\begin{tabular}{|c|c|c|c|c|c|c|c|c|c|c|c|}
\hline & EURO & WHO-5 & FEW-B & FEW-V & FEW-G & FEW-I & FEW $_{\text {Total }}$ & SOMS-7 & BDSI1 & BDSI2 & BDSI $_{\text {Total }}$ \\
\hline VBD Real & $0.668^{\star \star}$ & $0.626^{\star \star}$ & $0.779^{\star \star}$ & $0.649^{\star \star}$ & $0.637^{\star \star}$ & $0.596^{\star \star}$ & $739^{\star \star}$ & $-0.537^{\star \star}$ & $-0.332^{\star \star}$ & $-0.182^{\star \star}$ & $-0.334^{\star \star}$ \\
\hline $\mathrm{RBI}_{\text {Real }}$ & $-0.414^{\star \star}$ & $-0.280^{\star *}$ & $-0.386^{\star \star}$ & $-0.326^{\star \star}$ & $-0.389^{\star \star}$ & $-0.343^{\star \star}$ & $-0.398^{\star \star}$ & $0.306^{\star \star}$ & $0.499^{\star *}$ & $0.227^{\star \star}$ & $0.496^{\star \star}$ \\
\hline$V_{B D}$ Ideal & $0.524^{\star \star}$ & $0.397^{\star \star}$ & $0.561^{\star \star}$ & $0.447^{\star \star}$ & $0.435^{\star \star}$ & $0.398^{\star \star}$ & $0.512^{\star \star}$ & $-0.404^{\text {** }}$ & $-0.233^{\star \star}$ & $-0.124^{\star \star}$ & $-0.234^{\star *}$ \\
\hline $\mathrm{RBI}_{\text {/deal }}$ & $-0.328^{\star *}$ & $-0.199^{\star \star}$ & $-0.304^{\star \star}$ & $-0.255^{\star \star}$ & $-0.310^{\star *}$ & $0.279^{\star \star}$ & $-0.317^{\star \star}$ & $0.261^{\star \star}$ & $0.388^{\star \star}$ & $0.180^{\star \star}$ & $0.385^{\star \star}$ \\
\hline
\end{tabular}

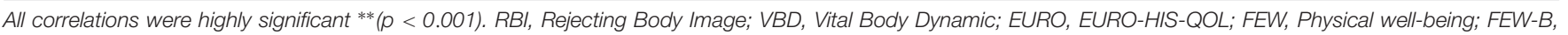
Resilience; FEW-V, Vitality; FEW-G, Enjoyment; FEW-I, Inner Peace; BDSI1, Body dimorphic symptoms; BDSI2, specific body parts.

TABLE 6 | Correlations between discrepancies of the real vs. ideal and related measures.

\begin{tabular}{|c|c|c|c|c|c|c|c|c|c|c|c|}
\hline & EURO & WHO & FEW-B & FEW-V & FEW-G & FEW-I & FEW $_{\text {Total }}$ & SOMS & FK1 & FK2 & $\mathrm{FKS}_{\text {Total }}$ \\
\hline $\mathrm{VBD}_{\text {dis }}$ & $-0.245^{\star \star}$ & $-0.224^{\star \star}$ & $-0.262^{\star \star}$ & $-0.204^{\star \star}$ & $-0.231^{\star \star}$ & $-0.226^{\star \star}$ & $-0.255^{\star \star}$ & $0.184^{\star \star}$ & $0.140^{\star \star}$ & $0.097^{\star \star}$ & $0.141^{\star \star}$ \\
\hline $\mathrm{RBI}_{\text {dis }}$ & $-0.128^{\star \star}$ & $-0.103^{\star *}$ & $-0.106^{\star \star}$ & $-0.072^{\star *}$ & $-0.120^{\star *}$ & $-0.113^{\star \star}$ & $-0.113^{\star \star}$ & $0.071^{*}$ & $0.140^{\star \star}$ & $0.084^{*}$ & $0.142^{\star \star}$ \\
\hline
\end{tabular}

All correlations were highly significant ** ( $<$ < 0.001). RBI dis, Discrepancy Rejecting Body Image; VBD dis, Vital Body Dynamic Discrepancy; EURO, EURO-HIS-QOL; FEW, Physical well-being; FEW-B, Resilience; FEW-V, Vitality; FEW-G, Enjoyment; FEW-I, Inner Peace; BDSI1, Body dimorphic symptoms; BDSI2, specific body parts. 
TABLE 7 | Normative percentile ranks for the VBD real version.

\begin{tabular}{|c|c|c|c|c|c|c|c|c|c|c|c|c|}
\hline \multirow[t]{3}{*}{ Sum Score } & \multicolumn{6}{|c|}{ Female } & \multicolumn{6}{|c|}{ Male } \\
\hline & \multicolumn{6}{|c|}{ Age in years } & \multicolumn{6}{|c|}{ Age in years } \\
\hline & $\begin{array}{c}18-29 \\
(n=215)\end{array}$ & $\begin{array}{c}30-39 \\
(n=239)\end{array}$ & $\begin{array}{c}40-49 \\
(n=219)\end{array}$ & $\begin{array}{c}50-59 \\
(n=186)\end{array}$ & $\begin{array}{c}60-69 \\
(n=207)\end{array}$ & $\begin{aligned} & \geq 70 \\
&(n=162)\end{aligned}$ & $\begin{array}{c}18-29 \\
(n=215)\end{array}$ & $\begin{array}{c}30-39 \\
(n=196)\end{array}$ & $\begin{array}{c}40-49 \\
(n=201)\end{array}$ & $\begin{array}{c}50-59 \\
(n=162)\end{array}$ & $\begin{array}{c}60-69 \\
(n=227)\end{array}$ & $\begin{array}{c}\geq 70 \\
(n=138)\end{array}$ \\
\hline 3 & 0 & 0 & 1 & 1 & 1 & 5 & 0 & 0 & 1 & 1 & 1 & 5 \\
\hline 4 & 1 & 1 & 2 & 2 & 2 & 8 & 0 & 1 & 2 & 2 & 2 & 7 \\
\hline 5 & 2 & 2 & 3 & 4 & 3 & 13 & 0 & 3 & 5 & 4 & 7 & 10 \\
\hline 6 & 4 & 3 & 5 & 8 & 10 & 23 & 1 & 5 & 7 & 6 & 11 & 17 \\
\hline 7 & 7 & 6 & 8 & 12 & 14 & 38 & 3 & 7 & 10 & 9 & 18 & 28 \\
\hline 8 & 12 & 8 & 13 & 18 & 24 & 49 & 3 & 8 & 18 & 15 & 22 & 33 \\
\hline 9 & 16 & 13 & 17 & 31 & 45 & 64 & 7 & 13 & 24 & 20 & 34 & 50 \\
\hline 10 & 23 & 21 & 29 & 42 & 56 & 77 & 12 & 19 & 34 & 30 & 48 & 65 \\
\hline 11 & 30 & 34 & 42 & 59 & 68 & 87 & 15 & 23 & 60 & 46 & 62 & 75 \\
\hline 12 & 47 & 59 & 71 & 80 & 87 & 96 & 33 & 45 & 76 & 65 & 87 & 92 \\
\hline 13 & 67 & 80 & 86 & 88 & 95 & 98 & 51 & 63 & 85 & 75 & 94 & 96 \\
\hline 14 & 80 & 90 & 94 & 95 & 98 & 99 & 67 & 77 & 85 & 86 & 97 & 99 \\
\hline 15 & 100 & 100 & 100 & 100 & 100 & 100 & 100 & 100 & 100 & 100 & 100 & 100 \\
\hline
\end{tabular}

VBD, Vital Body Dynamics.

TABLE 7a | Normative percentile ranks for the RBI real version.

\begin{tabular}{|c|c|c|c|c|c|c|c|c|c|c|c|c|}
\hline \multirow[t]{2}{*}{ Sum score } & \multicolumn{6}{|c|}{ Female } & \multicolumn{6}{|c|}{ Male } \\
\hline & \multicolumn{6}{|c|}{ Age in years } & \multicolumn{6}{|c|}{ Age in years } \\
\hline 3 & 29 & 31 & 23 & 23 & 26 & 30 & 48 & 46 & 38 & 41 & 40 & 34 \\
\hline 6 & 71 & 75 & 68 & 63 & 67 & 77 & 83 & 82 & 76 & 77 & 73 & 69 \\
\hline 7 & 83 & 80 & 79 & 76 & 76 & 86 & 89 & 88 & 85 & 84 & 80 & 78 \\
\hline 8 & 87 & 87 & 84 & 83 & 86 & 93 & 92 & 91 & 89 & 87 & 90 & 86 \\
\hline 9 & 92 & 93 & 90 & 90 & 94 & 96 & 93 & 95 & 93 & 92 & 95 & 93 \\
\hline 10 & 94 & 95 & 92 & 94 & 96 & 98 & 96 & 96 & 95 & 94 & 98 & 93 \\
\hline 15 & 100 & 100 & & 100 & & & 100 & 100 & 100 & & & \\
\hline
\end{tabular}

RBI, Rejecting Body Image.

reported (Schmidt et al., 2012). This outcome suggested, that being in discomfort with one's ideal body image and in struggle to accept the real body image leads to body dissatisfaction has negative consequences. In support of this, past evidence associates body image discrepancies (ideal vs. real) with a range of negative health outcomes such as depression and hypochondriasis (e.g., Cash and Smolak, 2011; Wilson et al., 2013; França et al., 2017; Becker et al., 2019). In addition, it seems plausible to assume that discrepancies between the real and the ideal body image, may lead to a state of cognitive dissonance, promoting internal discomfort and stress (Festinger,
1957; Dilakshini and Kumar, 2020). These fits comparable findings in previous studies (Benninghoven et al., 2007; Hrabosky and Grilo, 2007) confirming the growing evidence of body dissatisfaction (Halliwell et al., 2011; Wang et al., 2019) as a result of incongruences between beauty ideals and current body sizes. Some researchers even emphasized that ideal comparisons strongly affected body image, especially in women (Betz et al., 2019).

Strict measurement invariance across age and sex was found for the ideal version. This was also true for the real version when considering age, but not for sex. However, 
TABLE 7b | Normative percentile ranks for the VBD ideal.

\begin{tabular}{|c|c|c|c|c|c|c|c|c|c|c|c|c|}
\hline \multirow[t]{3}{*}{ Sum score } & \multicolumn{6}{|c|}{ Female } & \multicolumn{6}{|c|}{ Male } \\
\hline & \multicolumn{6}{|c|}{ Age in years } & \multicolumn{6}{|c|}{ Age in years } \\
\hline & $\begin{array}{c}18-29 \\
(n=215)\end{array}$ & $\begin{array}{c}30-39 \\
(n=239)\end{array}$ & $\begin{array}{c}40-49 \\
(n=219)\end{array}$ & $\begin{array}{c}50-59 \\
(n=186)\end{array}$ & $\begin{array}{c}60-69 \\
(n=207)\end{array}$ & $\begin{array}{c}\geq 70 \\
(n=162)\end{array}$ & $\begin{array}{c}18-29 \\
(n=215)\end{array}$ & $\begin{array}{c}30-39 \\
(n=196)\end{array}$ & $\begin{array}{c}40-49 \\
(n=201)\end{array}$ & $\begin{array}{c}50-59 \\
(n=162)\end{array}$ & $\begin{array}{c}60-69 \\
(n=227)\end{array}$ & $\begin{array}{c}\geq 70 \\
(n=138)\end{array}$ \\
\hline 3 & 0 & 0 & 0 & 0 & 0 & 4 & 0 & 0 & 0 & 2 & 1 & 4 \\
\hline 4 & 0 & 0 & 0 & 0 & 0 & 6 & 0 & 0 & 0 & 3 & 1 & 7 \\
\hline 5 & 1 & 1 & 2 & 1 & 2 & 12 & 0 & 0 & 0 & 4 & 4 & 9 \\
\hline 6 & 3 & 2 & 3 & 4 & 4 & 19 & 0 & 1 & 2 & 6 & 8 & 16 \\
\hline 7 & 6 & 4 & 5 & 8 & 11 & 30 & 1 & 4 & 4 & 9 & 13 & 20 \\
\hline 8 & 11 & 6 & 7 & 11 & 20 & 40 & 2 & 7 & 9 & 15 & 21 & 33 \\
\hline 9 & 18 & 12 & 16 & 23 & 34 & 51 & 8 & 11 & 15 & 24 & 34 & 45 \\
\hline 10 & 29 & 19 & 23 & 33 & 46 & 64 & 13 & 17 & 25 & 30 & 42 & 56 \\
\hline 11 & 37 & 36 & 35 & 46 & 57 & 77 & 20 & 25 & 35 & 41 & 54 & 73 \\
\hline 12 & 56 & 59 & 63 & 69 & 83 & 86 & 35 & 45 & 53 & 63 & 77 & 85 \\
\hline 13 & 70 & 76 & 76 & 82 & 89 & 92 & 47 & 59 & 67 & 77 & 85 & 92 \\
\hline 14 & 80 & 87 & 88 & 90 & 94 & 92 & 66 & 74 & 78 & 84 & 92 & 94 \\
\hline 15 & 100 & 100 & 100 & 100 & 100 & 100 & 100 & 100 & 100 & 100 & 100 & 100 \\
\hline
\end{tabular}

VBD, Vital Body Dynamics.

TABLE 7c | Normative percentile ranks for the RBI ideal.

\begin{tabular}{|c|c|c|c|c|c|c|c|c|c|c|c|c|}
\hline Sum score & \multicolumn{6}{|c|}{ Female } & \multicolumn{6}{|c|}{ Male } \\
\hline 3 & 25 & 25 & 23 & 26 & 21 & 28 & 44 & 39 & 33 & 36 & 28 & 30 \\
\hline 6 & 63 & 70 & 70 & 62 & 63 & 73 & 71 & 77 & 72 & 67 & 65 & 72 \\
\hline 7 & 74 & 78 & 77 & 73 & 78 & 81 & 80 & 83 & 81 & 72 & 75 & 83 \\
\hline 8 & 84 & 85 & 84 & 81 & 86 & 89 & 86 & 88 & 86 & 80 & 83 & 86 \\
\hline 9 & 91 & 90 & 92 & 88 & 94 & 94 & 93 & 94 & 92 & 86 & 93 & 92 \\
\hline 10 & 93 & 93 & 95 & 94 & 97 & 98 & 96 & 97 & 95 & 93 & 96 & 96 \\
\hline 15 & 100 & & & & 100 & & & & & & & \\
\hline
\end{tabular}

RBI, Rejecting Body Image.

partial invariance was established in this case. This is a relevant and novel finding regarding the measurement of body image, since this reveals that the measurement model is identical for these groups. If these prerequisites were not fulfilled, comparisons of latent and observed means and variances between groups would be questionable (Gregorich, 2006; Schmalbach and Zenger, 2019). Specifically, betweengroup equivalence of factor loadings and item intercepts is needed for comparisons of latent and observed means. On the other hand, merely the equivalence of factor loadings is needed to allow for comparisons between latent variances, but equivalence of both, loadings and item residual variances is required for meaningful comparisons of observed variances. We found small between-group intercept differences for several items when considering the real body image questionnaire.

The largest intercept deviation was exhibited for Item 8 ("Unhappy with one's figure").

This makes sense since compared to men, women are generally more unhappy with their body, even across age (Quittkat et al., 2019). Even though men are also affected (Frederick et al., 2012), it has been concluded that 
body dissatisfaction tends to be higher in women than in men (Betz et al., 2019; Quittkat et al., 2019; Radwan et al., 2019). Possible explanations are the particular propensity of women to "misperceive" their body weight (Chang and Christakis, 2001) and the higher relevance of appearance in women than in men (Quittkat et al., 2019), which recurrently manifests in an incremented eating disorder prevalence in women than in men (Galmiche et al., 2019).

Scalar invariance was then only obtained after relaxing the equality constraint for one item (Item 8), This means that-even given the same factor score-one will still find differences in the observed means between groups. As pointed out by Steinmetz (2013), observed means should thus not be taken at face value for the Rejecting Body Image subscale of the real body image questionnaire. Instead, researchers should examine latent means if they are interested in differences between sexes.

Evidence of validity was exhibited by means of correlations of the FKB-6 (both versions) with other related constructs. As expected, convergent validity was indicated by means of strong correlations between vital body dynamics and physical wellbeing, quality of life, and subjective well-being. This shows that VBD is well reflected in these qualities. The strongest correlation was shown between VBD and physical well-being properly emphasizing the physical component in this dimension. Previous studies demonstrated similar results, underlining the relevance of these findings (Clement and Löwe, 1996; Albani et al., 2006a,b, 2009). On the other hand, somatoform and body dysmorphic symptoms provide evidence of divergent validity, since they are negatively related to VBD. The weakest correlation was observed with somatoform symptoms. Consequently, VBD clearly distinguishes itself from body centered disturbances and complaints. Similar results were shown in previous research (Sack et al., 2002; Albani et al., 2006a, 2009). Convergent and divergent validity for the rejecting body image was also evident. Moderate to strong correlations with somatoform and body dysmorphic symptoms indicate convergent validity. The strongest correlation is observed with body dysmorphic symptoms. As a result, this highlights the aspect of body discomfort and preoccupation underlined in rejecting body image. Some researchers have reported comparable findings even among athletes (Daig et al., 2006, 2008; Dyl et al., 2006; Rief et al., 2006; Albani et al., 2009; Sarrar et al., 2010). Further, it was observed that the correlations in the ideal version, as expected, are similar to the ones in the real version, however, they are slightly smaller. An explanation for this, is that the ideal version of the FKB-6 is being compared to total scores (of the other scales) reflecting real and not ideal values of the participants.

Comparisons between sociodemographic variables revealed that in both versions age and employment were the most influential variables in terms of explaining differences in vital body dynamics. On the other hand, family status had the largest effect regarding rejecting body image (real version). This goes in line with literature on body image, showing changes in body image perception relevant to age, employment and family status (Grogan, 1999, 2017; Paeratakul et al., 2002; Albani et al., 2006a; Myers and Crowther, 2009; Klos and Sobal, 2013).

\section{Limitations}

The present study utilized primarily a statistical approach grounded in classical test theory (CTT). A growing body of research has discussed differences between CTT and an alternative approach: Item response theory (IRT; Embretson and Reise, 2013). In most cases, the two approaches lead to similar results (Fan, 1998; Kamata and Bauer, 2008; Progar et al., 2008; Sébille et al., 2010). Nonetheless, we acknowledge that our focus on CTT over IRT paints a potentially incomplete picture of the scale construction process. Thus, future validation studies could benefit from implementing the IRT. In addition, the validation of the present scale is based on non-clinical data. We included and analyzed data of the general population and provided norm values, which is useful for the evaluation of clinical samples. Notwithstanding, following studies could enrich the validity of the scale by focusing on providing psychometric properties based on clinical samples.

\section{CONCLUSION}

In the face of growing body image disturbances and its pervasive effects on physical and mental health, there is a crucial demand in the field of body image assessment to provide proper measures, especially given the need of such in German-speaking populations. The FKB-6 aims to meet these demands providing an economic and a validated tool that is best of use in in research settings and economic clinical assessments. The short versions of the FKB-20 are valid and reliable instruments that measure body image issues by means of affective and cognitive variables. They facilitate and economize diagnosis and aids treatment in clinical contexts. Its brevity provides advantages for large scientific surveys.

\section{DATA AVAILABILITY STATEMENT}

The raw data supporting the conclusions of this article will be made available by the authors, without undue reservation, to any qualified researcher.

\section{ETHICS STATEMENT}

Ethical review and approval was not required for the study on human participants in accordance with the local legislation and institutional requirements. The patients/participants provided their written informed consent to participate in this study. The methods of data collection were in accordance with the Helsinki Declaration of 1975 (as revised in 1983). 


\section{AUTHOR CONTRIBUTIONS}

IS contributed to the writing of the draft of the manuscript and managing information of new editions and corrections. CA was responsible for data collection and conception data management. EB contributed to the design of the study idea. BS contributed to the data analysis and discussion. KP and HB contributed to the writing and editing of the manuscript and literature review. $\mathrm{MZ}$ contributed to the writing and editing of the manuscript. All authors have contributed to the preparation of the manuscript and report of results, and approve the submitted manuscript for publication.

\section{REFERENCES}

Albani, C., Blaser, G., Geyer, M., Daig, I., Schmutzer, G., Bailer, H., et al. (2006a). Überprüfung und Normierung des" Fragebogen zum Körperbild"(FKB20) von Clement und Löwe (1996) an einer repräsentativen deutschen Bevölkerungsstichprobe. Z. Med. Psychol. 15, 99-109.

Albani, C., Blaser, G., Geyer, M., Schmutzer, G., Hinz, A., Bailer, H., et al. (2006b). Validierung und Normierung des „Fragebogen zur Erfassung des körperlichen Wohlbefindens"(FEW-16) von Kolip und Schmidt an einer repräsentativen deutschen Bevölkerungsstichprobe. PPmP Psychother. Psychos.Med. Psychol. 56, $172-181$.

Albani, C., Gunzelmann, T., and Brähler, E. (2009). Körperbild und körperliches Wohlbefinden im Alter. Z. Gerontol. Geriatrie 42, 236-244.

Baker, F. B. (2001). The Basics of Item Response Theory. College Park, MD: ERIC Clearinghouse on Assessment and Evaluation, University of Maryland.

Bech, P., Gudex, C., and Johansen, K. S. (1996). The WHO (Ten) well-being index: validation in diabetes. Psychother. Psychosom. 65, 183-190. doi: 10.1159/ 000289073

Becker, C. B., Verzijl, C. L., Kilpela, L. S., Wilfred, S. A., and Stewart, T. (2019). Body image in adult women: associations with health behaviors, quality of life, and functional impairment. J. Health Psychol. 24, 1536-1547. doi: 10.1177/ 1359105317710815

Bliese, M. P. (2016). Package Multilevel.

Benninghoven, D., Tadiæ, V., Kunzendorf, S., and Jantschek, G. (2007). Körperbilder männlicher Patienten mit Essstörungen. PPmP Psychother., Psychos.Med. Psychol. 57, 120-127.

Betz, D. E., Sabik, N. J., and Ramsey, L. R. (2019). Ideal comparisons: body ideals harm women's body image through social comparison. Body Image 29, 100-109. doi: 10.1016/j.bodyim.2019.03.004

Brähler, E., Mühlan, H., Albani, C., and Schmidt, S. (2007). Teststatistischeprüfung und Normierung der deutschen Versionen des EUROHIS-QOL Lebensqualität-Index und des WHO-5 Wohlbefindens-index. Diagnostica 53, 83-96. doi: 10.1026/0012-1924.53.2.83

Broesseau-liard, P. E., Savalei, V., and Li, L. (2012). An investigation of the sample performance of two nonnormality corrections for RMSEA. Multivariate Behav. Res. 47, 904-930. doi: 10.1080/00273171.2012.715252

Brosseau-Liard, P. E., and Savalei, V. (2014). Adjusting incremental fit indices for nonnormality. Multiv. Behav. Res. 49, 460-470. doi: 10.1080/00273171.2014. 933697

Buhlmann, U., Teachman, B. A., Naumann, E., Fehlinger, T., and Rief, W. (2009). The meaning of beauty: implicit and explicit self-esteem and attractiveness beliefs in body dysmorphic disorder. J. Anxiety Disord. 23, 694-702. doi: 10. 1016/j.janxdis.2009.02.008

Carlson, J. D. (2004). Body image among adolescent girls and boys: a longitudinal study. Dev. Psychol. 40, 823-835. doi: 10.1037/0012-1649.40. 5.823

Cash, T. (2002). "Cognitive-behavioural perspectives on body image," in Body Image: A Handbook of Theory, Research, and Clinical Practice, eds T. F. Cash and T. Pruzinsky (New York, NY: Guilford), 38-46.

\section{FUNDING}

Open Access Funding by the Publication Fund of the TU Dresden.

\section{ACKNOWLEDGMENTS}

I would like to kindly thank Professor Berth and the TU Dresden for taking care of all the costs related to the publication process in the Journal Frontiers.

Cash, T. F. (2012). Cognitive-behavioral perspectives on body image. Encyclopedia Body Image Hum. Appearance 2012, 334-342. doi: 10.1016/b978-0-12-3849250.00054-7

Cash, T. F. (2017). Body image: a joyous journey [Editorial]. Body Image 23, A1-A2. doi: 10.1016/j.bodyim.2017.11.001

Cash, T. F., and Fleming, E. C. (2002). The impact of body image experiences: development of the body image quality of life inventory. Int. J. Eat. Disord. 31, 455-460. doi: 10.1002/eat.10033

Cash, T. F., and Smolak, L. (eds) (2011). Body Image: A Handbook of Science, Practice, and Prevention. New York, NY: Guilford Press.

Chalmers, R. P. (2012). mirt: a multidimensional item response theory package for the R environment. J. Stat. Softw. 48, 1-29. doi: 10.18637/jss.v048.i06

Chang, V. W., and Christakis, N. A. (2001). Extent and determinants of discrepancy between self-evaluations of weight status and clinical standards. J. Gen. Intern. Med. 16, 538-543. doi: 10.1046/j.1525-1497.2001.016008538.x

Chen, F. F. (2007). Sensitivity of goodness of fit indexes to lack of measurement invariance. Struct. Equ. Model. Multidiscip. J. 14, 464-504. doi: 10.1080/ 10705510701301834

Clement, U., and Löwe, B. (1996). Die Validierung des FKB-20 als Instrument zur Erfassung von Körperbildstörungen bei psychosomatischen patienten. PPmP Psychother. Psychos.Med. Psychol. 46, 254-259.

Daig, I., Albani, C., Rief, W., and Brähler, E. (2006). Körperdysmorphe Beschwerden: Welche Rolle spielt die Diskrepanz zwischen Ideal-und Realkörperbild? PPmP Psychother. Psychos.Med. Psychol. 56, 259-267. doi: 10.1055/s-2006-932570

Daig, I., Burkert, S., Albani, C., Martin, A., and Brähler, E. (2008). Zusammenhang zwischen körperdysmorphen Beschwerden, Körperbild und Selbstaufmerksamkeit an einer repräsentativen Stichprobe. PPmP Psychother. Psychos.Med. Psychol. 58, 16-22. doi: 10.1055/s-2007-970945

De Wit, M., Pouwer, F., Gemke, R. J., Delemarre-Van De Waal, H. A., and Snoek, F. J. (2007). Validation of the WHO-5 Well-Being Index in adolescents with type 1 diabetes. Diabetes Care 30, 2003-2006. doi: 10.2337/dc07-0447

Di Cara, M., Buono, V. L., Corallo, F., Cannistraci, C., Rifici, C., Sessa, E., et al. (2019). Body image in multiple sclerosis patients: a descriptive review. Neurol. Sci. 40, 923-928. doi: 10.1007/s10072-019-3722-1

Dilakshini, V. L., and Kumar, S. M. (2020). Cognitive dissonance: a psychological unrest. Curr. J. Appl. Sci. Technol. 39, 54-60. doi: 10.9734/cjast/2020/ v39i3030970

Dunn, T. J., Baguley, T., and Brunsden, V. (2014). From alpha to omega: a practical solution to the pervasive problem of internal consistency estimation. Br. J. Psychol. 105, 399-412. doi: 10.1111/bjop.12046

Dyl, J., Kittler, J., Phillips, K. A., and Hunt, J. I. (2006). Body dysmorphic disorder and other clinically significant body image concerns in adolescent psychiatric inpatients: prevalence and clinical characteristics. Child Psychiatry Hum. Dev. 36, 369-382. doi: 10.1007/s10578-006-0008-7

Embretson, S. E., and Reise, S. P. (2013). Item Response Theory for Psychologists. Hillsdale, NJ: Erlbaum.es, 923-928.

Esser, P., Mehnert, A., Johansen, C., Hornemann, B., Dietz, A., and Ernst, J. (2018). Body image mediates the effect of cancer-related stigmatization on depression: a new target for intervention. Psycho Oncol. 27, 193-198. doi: 10.1002/pon.4494 
Fan, X. (1998). Item response theory and classical test theory: an empirical comparison of their item/person statistics. Educ. Psychol. Meas. 58, 357-381. doi: $10.1177 / 0013164498058003001$

Fatt, S. J., Mond, J., Bussey, K., Griffiths, S., Murray, S. B., Lonergan, A., et al. (2020). Seeing yourself clearly: Self-identification of a body image problem in adolescents with an eating disorder. Early Intervent. Psychiatry [Epub ahead of print].

Federal Statistical Office of Germany (2019). Bevölkerung [Population]. Available online at: https://www.destatis.de/DE/Themen/Gesellschaft-Umwelt/ Bevoelkerung/_inhalt.html (accessed June 26, 2020).

Festinger, L. (1957). A Theory of Cognitive Dissonance, Vol. 2. Palo Alto, CA: Stanford university press.

França, K., Roccia, M. G., Castillo, D., ALHarbi, M., Tchernev, G., Chokoeva, A., et al. (2017). Body dysmorphic disorder: history and curiosities. Wien. Med. Wochenschr. 167, 5-7. doi: 10.1007/s10354-017-0544-8

Frederick, D. A., Jafary, A. M., Gruys, K., and Daniels, E. A. (2012). "Surveys and the epidemiology of body image dissatisfaction," in Encyclopedia of body IMAGE and Human Appearance, ed. T. F Cash (Cambridge, MA: Academic Press), 766-774. doi: 10.1016/b978-0-12-384925-0.00121-8

Galmiche, M., Déchelotte, P., Lambert, G., and Tavolacci, M. P. (2019). Prevalence of eating disorders over the 2000-2018 period: a systematic literature review. Am. J. Clin. Nutr. 109, 1402-1413. doi: 10.1093/ajen/nqy342

Glauert, R., Rhodes, G., Byrne, S., Fink, B., and Grammer, K. (2009). Body dissatisfaction and the effects of perceptual exposure on body norms and ideals. Int. J. Eat. Disord. 42, 443-452. doi: 10.1002/eat.20640

Gregorich, S. E. (2006). Do self-report instruments allow meaningful comparisons across diverse population groups? Testing measurement invariance using the confirmatory factor analysis framework. Med. Care 44(11 Suppl. 3), S78.

Grogan, S. (1999). Body Image. London: Routledge.

Grogan, S. (2017). Body Image. London: Routledge.

Groot, L. D. (2020). The Relationship Between Body Dissatisfaction and Sexual Dysfunction: The Mediating role of Depression. Master's thesis, Utrecht University, Utrecht.

Grübel, R. (2003). Die Wirksamkeit der Feldenkrais-Methode bei KrebsBetroffenen. Erfahrungsheilkunde 52, 71-83. doi: 10.1055/s-2003-37391

Gunzelmann, T., Schmidt, S., Albani, C., and Brähler, E. (2006). Lebensqualität und Wohlbefinden im Alter. Z. Gerontopsychol. Psychiatr. 19, 7-15.

Hair, J. F., Black, W. C., Babin, B. J., and Anderson, R. E. (2013). Multivariate Data Analysis: Pearson New International Edition. London: Pearson Higher Education.

Halliwell, E., Malson, H., and Tischner, I. (2011). Are contemporary media images which seem to display women as sexually empowered actually harmful to women? Psychol. Women Q. 35, 38-45. doi: 10.1177/0361684310385217

Hessel, A., Geyer, M., and Brähler, E. (2002). Somatoforme Beschwerden in der Bevölkerung Deutschlands/Somatoform complaints in the German population. Z. Psychos. Med. Psychother. 48, 38-58. doi: 10.13109/zptm.2002. 48.1.38

Heun, R., Bonsignore, M., Barkow, K., and Jessen, F. (2001). Validity of the fiveitem WHO Well-Being Index (WHO-5) in an elderly population. Eur. Arch. Psychiatry Clin. Neurosci. 251, 27-31. doi: 10.1007/bf03035123

Higgins, E. T. (1987). Self-discrepancy: a theory relating self and affect. Psychol. Rev. 94, 319-340. doi: 10.1037/0033-295X.94.3.319

Hiller, W., Rief, W., and Brähler, E. (2006). Somatization in the population: from mild bodily misperceptions to disabling symptoms. Soc. Psychiatry Psychiatr. Epidemiol. 41, 704-712. doi: 10.1007/s00127-006-0082-y

Hinz, A., Blaser, G., Schmutzer, G., Bailer, H., Grulke, N., Brähler, E., et al. (2010). Überprüfung und Normierung des "Fragebogen zur Erfassung dispositionaler Selbstaufmerksamkeit"(SAM) an einer repräsentativen deutschen Bevölkerungsstichprobe. Klinis. Diagn. Eval. 3, 382-395.

Horn, J. L. (1965). A rationale and test of the number of factors in factor analysis. Psychometrika 30, 179-185. doi: 10.1007/bf02289447

Hotter, A., Mangweth, B., Kemmler, G., Fiala, M., Kinzl, J., and Biebl, W. (2003). Therapeutic outcome of adjustable gastric banding in morbid obese patients. Eating Weight Disord. Stud. Anorexia Bulimia Obes. 8, 218-224. doi: 10.1007/ bf 03325017

Hrabosky, J. I., and Grilo, C. M. (2007). Body image and eating disordered behavior in a community sample of Black and Hispanic women. Eat. Behav. 8, 106-114. doi: 10.1016/j.eatbeh.2006.02.005
Hu, L. T., and Bentler, P. M. (1999). Cutoff criteria for fit indexes in covariance structure analysis: conventional criteria versus new alternatives. Struct. Equ. Model. Multidiscipl. J. 6, 1-55. doi: 10.1080/10705519909540118

Joraschky, P., Loew, T., and Röhricht, F. (eds) (2018). Körpererleben und Körperbild: Ein Handbuch zur Diagnostik. Stuttgart: Klett-Cotta.

Jorgensen, T. D., Pornprasertmanit, S., Schoemann, A. M., Rosseel, Y., Miller, P., Quick, C., et al. (2020). Package SemTools.

Kamata, A., and Bauer, D. J. (2008). A note on the relation between factor analytic and item response theory models. Struct. Equ. Model. Multidiscip. J. 15, 136-153. doi: 10.1080/10705510701758406

Kim, H. Y. (2013). Statistical notes for clinical researchers: assessing normal distribution (2) using skewness and kurtosis. Restorative Dent. Endodontics 38, 52-54. doi: 10.5395/rde.2013.38.1.52

Kling, J., Kwakkenbos, L., Diedrichs, P. C., Rumsey, N., Frisén, A., Brandão, M. P., et al. (2019). Systematic review of body image measures. Body Image 30, 170-211. doi: 10.1016/j.bodyim.2019.06.006

Klos, L. A., and Sobal, J. (2013). Marital status and body weight, weight perception, and weight management among US adults. Eat. Behav. 14, 500-507. doi: 10. 1016/j.eatbeh.2013.07.008

Kolip, P., and Schmidt, B. (1999). Der Fragebogen zur Erfassung körperlichen Wohlbefindens (FEW 16): Konstruktion und erste Validierung. Zeitschrift für Gesundheitspsychologie 7, 77-87. doi: 10.1026//0943-8149.7.2.77

Krieger, T., Zimmermann, J., Huffziger, S., Ubl, B., Diener, C., Kuehner, C., et al. (2014). Measuring depression with a well-being index: further evidence for the validity of the WHO Well-Being Index (WHO-5) as a measure of the severity of depression. J. Affect. Disord. 156, 240-244. doi: 10.1016/j.jad.2013.12.015

Löwe, B., Breining, K., Wilke, S., Wellmann, R., Zipfel, S., and Eich, W. (2002). Quantitative and qualitative effects of Feldenkrais, progressive muscle relaxation, and standard medical treatment in patients after acute myocardial infarction. Psychother. Res. 12, 179-191. doi: 10.1093/ptr/12.2.179

Löwe, B., and Clement, U. (1996). Der Fragebogen zum koerperbild (FKB20). literaturueberblick, beschreibung und pruefung eines messinstrumentes. Diagnostica Göttingen 42, 352-376.

Löwe, B., Gräfe, K., Kroenke, K., Zipfel, S., Quenter, A., Wild, B., et al. (2003). Predictors of psychiatric comorbidity in medical outpatients. Psychosom Med. 65, 764-770. doi: 10.1097/01.psy.0000079379.39918.17

McCaulay, M., Mintz, L., and Glenn, A. A. (1988). Body image, self-esteem, and depression-proneness: closing the gender gap. Sex Roles 18, 381-391. doi: $10.1007 /$ bf00288390

McLean, S. A., and Paxton, S. J. (2019). Body image in the context of eating disorders. Psychiatr. Clin. 42, 145-156.

McNeish, D., An, J., and Hancock, G. R. (2018). The thorny relation between measurement quality and fit index cutoffs in latent variable models. J. Pers. Assess. 100, 43-52. doi: 10.1080/00223891.2017.1281286

Milfont, T. L., and Fischer, R. (2010). Testing measurement invariance across groups: applications in cross-cultural research. Int. J. Psychol. Res. 3, 111-130. doi: $10.21500 / 20112084.857$

Mills, J. S., Shannon, A., and Hogue, J. (2017). Beauty, body image, and the media. Percept. Beauty 8, 145-157.

Mölbert, S. C., Thaler, A., Mohler, B. J., Streuber, S., Romero, J., Black, M. J., et al. (2018). Assessing body image in anorexia nervosa using biometric self-avatars in virtual reality: attitudinal components rather than visual body size estimation are distorted. Psychol. Med. 48, 642-653. doi: 10.1017/S0033291717002008

Mond, J., Mitchison, D., Latner, J., Hay, P., Owen, C., and Rodgers, B. (2013). Quality of life impairment associated with body dissatisfaction in a general population sample of women. BMC Public Health 13:920. doi: 10.1186/14712458-13-920

Myers, T. A., and Crowther, J. H. (2009). Social comparison as a predictor of body dissatisfaction: a meta-analytic review. J. Abnorm. Psychol. 118, 683-698. doi: $10.1037 / \mathrm{a} 0016763$

Nagar, I., and Virk, R. (2017). The struggle between the real and ideal: impact of acute media exposure on body image of young Indian women. SAGE Open 7:2158244017691327.

Nichols, T. E., Damiano, S. R., Gregg, K., Wertheim, E. H., and Paxton, S. J. (2018). Psychological predictors of body image attitudes and concerns in young children. Body Image 27, 10-20. doi: 10.1016/j.bodyim.2018. 08.005

Nunally, J. C., and Bernstein, I. H. (1994). Psychological Theory. 
Nye, C. D., and Drasgow, F. (2011). Assessing goodness of fit: simple rules of thumb simply do not work. Organ. Res. Methods 14, 548-570. doi: 10.1177/ 1094428110368562

Paeratakul, S., White, M. A., Williamson, D. A., Ryan, D. H., and Bray, G. A. (2002). Sex, race/ethnicity, socioeconomic status, and BMI in relation to self-perception of overweight. Obes. Res. 10, 345-350. doi: 10.1038/oby.2002.48

Peterson, C. M., Matthews, A., Copps-Smith, E., and Conard, L. A. (2017). Suicidality, self-harm, and body dissatisfaction in transgender adolescents and emerging adults with gender dysphoria. Suicide Life Threat. Behav. 47, 475-482. doi: $10.1111 /$ sltb. 12289

Power, M., Bullinger, M., and Harper, A. (1999). The world health organization WHOQOL-100. Health Psychol. 18, 495-505. doi: 10.1037/0278-6133.18.5.495

Progar, Š, Sočan, G., and Peč, M. (2008). An empirical comparison of item response theory and classical test theory. Horizons Psychol. 17, 5-24.

Quittkat, H. L., Hartmann, A. S., Düsing, R., Buhlmann, U., and Vocks, S. (2019). Body dissatisfaction, importance of appearance and body appreciation in men and women over the lifespan. Front. Psychiatry 10:864. doi: 10.3389/fpsyt.2019. 00864

Radwan, H., Hasan, H. A., Ismat, H., Hakim, H., Khalid, H., Al-Fityani, L., et al. (2019). Body mass index perception, body image dissatisfaction and their relations with weight-related behaviors among university students. Int. J. Environ. Res. Public Health 16:1541. doi: 10.3390/ijerph16091541

Revelle, W. (2018). psych: Procedures for Personality and Psychological Research. Evanston, IL: Northwestern University.

Rief, W., Buhlmann, U., Wilhelm, S., Borkenhagen, A. D. A., and Brähler, E. (2006). The prevalence of body dysmorphic disorder: a population-based survey. Psychol. Med. 36, 877-885. doi: 10.1017/s0033291706007264

Rief, W., and Hiller, W. (2003). A new approach to the assessment of the treatment effects of somatoform disorders. Psychosomatics 44, 492-498. doi: 10.1176/appi. psy.44.6.492

Rief, W., Hiller, W., and Heuser, J. (1997). SOMS-Das Screening für Somatoforme Störungen: Manual zum Fragebogen (SOMS-The Screening for Somatoform Symptoms). Bern: Huber-Verlag.

Rosseel, Y. (2012). lavaan: an R package for structural equation modeling. J. Stat. Softw. 48, 1-36. doi: 10.1002/9781119579038.ch1

Sabiston, C. M., Pila, E., Vani, M., and Thogersen-Ntoumani, C. (2019). Body image, physical activity, and sport: a scoping review. Psychol. Sport Exerc. 42, 48-57. doi: 10.1016/j.psychsport.2018.12.010

Sack, M., Henninger, S., and Lamprecht, F. (2002). Veränderungen von Körperbild und Körpererleben bei essgestörten und nichtessgestörten Patienten im Verlauf einer stationären Psychotherapie. Psychother. Psychos. Med. Psychol. 52, 64-69. doi: 10.1055/s-2002-20182

Saiphoo, A. N., and Vahedi, Z. (2019). A meta-analytic review of the relationship between social media use and body image disturbance. Comput. Hum. Behav. 101, 259-275. doi: 10.1016/j.chb.2019.07.028

Sarrar, L., Schneider, N., Bayios, V., Pfeiffer, E., and Lehmkuhl, U. (2010). Körperbild und Körperzufriedenheit im Leistungssport. Sportwissenschaft 40, 262-267.

Sarwer, D. B., Thompson, J. K., and Cash, T. F. (2005). Body image and obesity in adulthood. Psychiatr. Clin. 28, 69-87.

Satorra, A., and Bentler, P. M. (2001). A scaled difference chi-square test statistic for moment structure analysis. Psychometrika 66, 507-514. doi: 10.1007/ bf02296192

Schermelleh-Engel, K., Moosbrugger, H., and Müller, H. (2003). Evaluating the fit of structural equation models: tests of significance and descriptive goodness-offit measures. Methods Psychol. Res. Online 8, 23-27.

Schieber, K., and Martin, A. (2016). Die körperdysmorphe störung: aktuelle entwicklungen zu diagnostik, störungswissen und therapie. Psych Up2date 10, 31-42. doi: 10.1055/s-0041-105934

Schmalbach, B., Irmer, J. P., and Schultze, M. (2019). ezCutoffs: Fit Measure Cutoffs in SEM. $R$ package version 1.0.1. Available online at: https://CRAN.R-project. org/package $=$ ezCutoffs (accessed June 26, 2020).

Schmalbach, B., and Zenger, M. (2019). Prüfung der Messinvarianz von Fragebögen alsnotwendige Grundlage für Mittelwertvergleiche. PPmP Psychother.Psychos.Med. Psychol. 69, 427-428. doi: 10.1055/a-0887-5920

Schmidt, S., Mühlan, H., and Power, M. (2006). The EUROHIS-QOL 8-item index: psychometric results of a cross-cultural field study. Eur. J. Public Health 16, 420-428. doi: 10.1093/eurpub/cki155
Schmidt, S., Petermann, F., Brähler, E., Stöbel-Richter, Y., and Koglin, U. (2012). Körperbildwahrnehmung als Risikofaktor für Chronischen Stress. Boston, MA: Kindheit und Entwicklung.

Schultze, M. (2019). stuart: Subtests Using Algorithmic Rummaging Techniques. $R$ package version 0.8.0. Available online at: https:/CRAN.R-project.org/ package=stuart (accessed June 26, 2020).

Sébille, V., Hardouin, J. B., Le Néel, T., Kubis, G., Boyer, F., Guillemin, F., et al. (2010). Methodological issues regarding power of classical test theory (CTT) and item response theory (IRT)-based approaches for the comparison of patient-reported outcomes in two groups of patients-a simulation study. BMC Med. Res. Methodol. 10:24. doi: 10.1186/1471-228810-24

Sinclair, S. L., and Myers, J. E. (2004). The relation between objectified body consciousness and wellness in a group of college women. J. College Counsel. 7, 150-161. doi: 10.1002/j.2161-1882.2004.tb00246.x

Skevington, S. M., Lotfy, M., and O'Connell, K. (2004). The World Health Organization's WHOQOL-BREF quality of life assessment: psychometric properties and results of the international field trial. A report from the WHOQOL group. Qual. Life Res. 13, 299-310. doi: 10.1023/b:qure.0000018486. 91360.00

Slade, P. D. (1994). What is body image?. Behav. Res. Ther. 32, 497-502.

Steenkamp, J. B. E., and Baumgartner, H. (1998). Assessing measurement invariance in cross-national consumer research. J. Consum. Res. 25, 78-90. doi: 10.1086/209528

Steinfeld, B., Bauer, A., Waldorf, M., Hartmann, A. S., and Vocks, S. (2017). Diagnostik der Körperbildstörung. Psychotherapeut 62, $164-182$.

Steinmetz, H. (2013). Analyzing observed composite differences across groups: is partial measurement invariance enough? Methodology 9, 1-12. doi: 10.1027/ 1614-2241/a000049

Swami, V., Weis, L., Barron, D., and Furnham, A. (2018). Positive body image is positively associated with hedonic (emotional) and eudaimonic (psychological and social) well-being in British adults. J. Soc. Psychol. 158, 541-552. doi: 10.1080/00224545.2017.1392278

Tesar, N., Baumhackl, U., Kopp, M., and Günther, V. (2003). Effects of psychological group therapy in patients with multiple sclerosis. Acta Neurol. Scand. 107, 394-399. doi: 10.1034/j.1600-0404.2003.00 077.x

Thompson, J. K. (2004). The (mis)measurement of body image: ten strategies to improve assessment for applied and research purposes. Body Image Int. J. Res. 1, 7-14. doi: 10.1016/s1740-1445(03)00004-4

Thompson, J. K., and Schaefer, L. M. (2019). Thomas F. cash: a multidimensional innovator in the measurement of body image; Some lessons learned and some lessons for the future of the field. Body Image 31, 198-203. doi: 10.1016/j. bodyim.2019.08.006

Tiggemann, M. (2004). Body image across the adult life span: stability and change. Body Image 1, 29-41. doi: 10.1016/s1740-1445(03)00002-0

Topp, C. W., Østergaard, S. D., Søndergaard, S., and Bech, P. (2015). The WHO-5 Well-Being Index: a systematic review of the literature. Psychother. Psychos. 84, 167-176. doi: 10.1016/S1740-1445(03)00002-0

Vashi, N. A. (2016). Obsession with perfection: body dysmorphia. Clin. Dermatol. 34, 788-791. doi: 10.1016/j.clindermatol.2016. 04.006

Veleva, B. I., van Bezooijen, R. L., Chel, V. G., Numans, M. E., and Caljouw, M. A. (2018). Effect of ultraviolet light on mood, depressive disorders and wellbeing. Photodermatol. Photoimmunol. Photomed. 34, 288-297. doi: 10.1111/ phpp.12396

Wang, S. B., Haynos, A. F., Wall, M. M., Chen, C., Eisenberg, M. E., and NeumarkSztainer, D. (2019). Fifteen-year prevalence, trajectories, and predictors of body dissatisfaction from adolescence to middle adulthood. Clin. Psychol. Sci. 7, 1403-1415. doi: 10.1177/2167702619859331

Williams, E. F., Cash, T. F., and Santos, M. T. (2004). "Positive and negative body image: precursors, correlates, and consequences," in Proceedings of the 38th annual Association for the Advancement of Behavior Therapy, Thousand Oaks, CA, 285-297.

Wilson, R. E., Latner, J. D., and Hayashi, K. (2013). More than just body weight: the role of body image in psychological and physical functioning. Body Image 10, 644-647. doi: 10.1016/j.bodyim.2013.04.007 
Zanon, A., Tomassoni, R., Gargano, M., and Granai, M. G. (2016). Body image and health behaviors: is there a relationship between lifestyles and positive body image. Clin. Ter. 167, 63-69.

Zhang, G., Jiang, G., Hattori, M., and Trichtinger, L. (2019). EFAutilities: Utility Functions for Exploratory Factor Analysis. $R$ package version 2.0.0. Available online at: https://CRAN.R-project.org/package=EFAutilities (accessed June 26, 2020).

Ziser, K., Finklenburg, C., Behrens, S. C., Giel, K. E., Becker, S., Skoda, E. M., et al. (2019). Perceived stress mediates the relationship of body image and depressive symptoms in individuals with obesity. Front. Psychiatry 10:852. doi: $10.3389 /$ fpsyt.2019.00852
Conflict of Interest: The authors declare that the research was conducted in the absence of any commercial or financial relationships that could be construed as a potential conflict of interest.

Copyright (c) 2020 Schmalbach, Schmalbach, Zenger, Berth, Albani, Petrowski and Brähler. This is an open-access article distributed under the terms of the Creative Commons Attribution License (CC BY). The use, distribution or reproduction in other forums is permitted, provided the original author(s) and the copyright owner(s) are credited and that the original publication in this journal is cited, in accordance with accepted academic practice. No use, distribution or reproduction is permitted which does not comply with these terms. 